\title{
Erratum
}

\section{Erratum: Gill and Hillel, Rapid Adaptation to Changing Mechanical Load by Ordered Recruitment of Identified Motor Neurons}

In the article "Rapid Adaptation to Changing Mechanical Load by Ordered Recruitment of Identified Motor Neurons," by Jeffrey P. Gill and Hillel J. Chiel, which was published online on April 24, 2020, the authors would like to address the following error.

The in-text citation in the last sentence of the Materials and Methods section links to the incorrect reference, which was also omitted from the References. The citation appearing as "(Gill and Chiel, 2020)" should link to the following: Gill J, Chiel H (2020) Data for Gill \& Chiel 2020: Rapid adaptation to changing mechanical load by ordered recruitment of identified motor neurons. G-Node. doi:10.12751/g-node.134e2c. The online version has been corrected.

https://doi.org/10.1523/ENEURO.0322-20.2020 